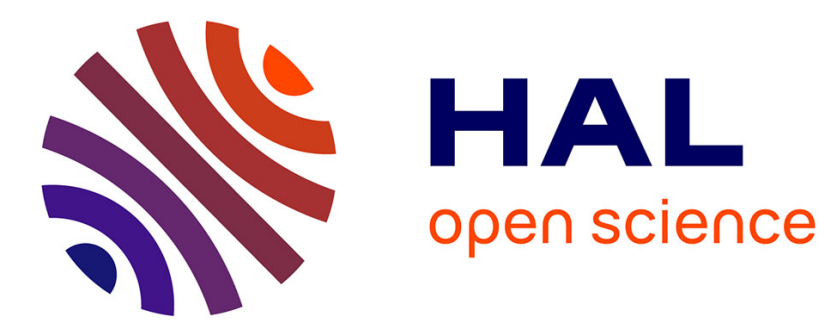

\title{
Transactions in the European Carbon Market: a Bubble of Compliance in a Whirlpool of Speculation
}

\author{
Nathalie Berta, Emmanuelle Gautherat, Ozgur Gun
}

\section{To cite this version:}

Nathalie Berta, Emmanuelle Gautherat, Ozgur Gun. Transactions in the European Carbon Market: a Bubble of Compliance in a Whirlpool of Speculation. 2015. halshs-01224552

\section{HAL Id: halshs-01224552}

https://shs.hal.science/halshs-01224552

Submitted on 4 Nov 2015

HAL is a multi-disciplinary open access archive for the deposit and dissemination of scientific research documents, whether they are published or not. The documents may come from teaching and research institutions in France or abroad, or from public or private research centers.
L'archive ouverte pluridisciplinaire HAL, est destinée au dépôt et à la diffusion de documents scientifiques de niveau recherche, publiés ou non, émanant des établissements d'enseignement et de recherche français ou étrangers, des laboratoires publics ou privés. 


\section{Documents de Travail du
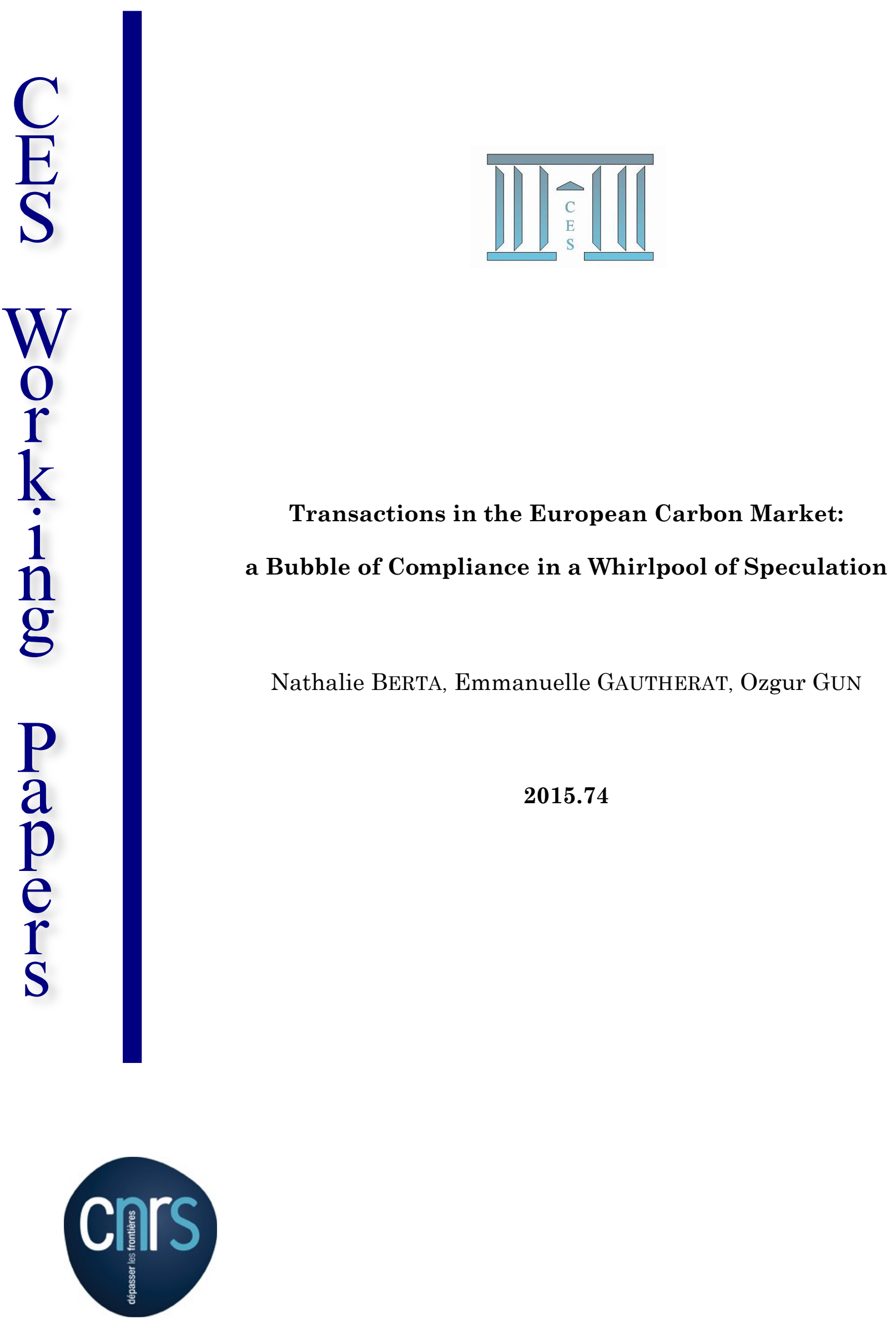

Maison des Sciences Économiques, 106-112 boulevard de L'Hôpital, 75647 Paris Cedex 13 http://centredeconomiesorbonne.univ-paris1.fr/ 


\title{
Transactions in the European Carbon Market:
}

\section{a Bubble of Compliance in a Whirlpool of Speculation}

\author{
Nathalie Berta ${ }^{\mathrm{i}}$, Emmanuelle Gautherat ${ }^{\mathrm{ii}}$ et Ozgur Gun ${ }^{\mathrm{ii}}$
}

\begin{abstract}
:
The European Union Emissions Trading Scheme (EU ETS) is supposed to help regulated installations to cover their $\mathrm{CO}_{2}$ emissions by trading in allowances. In practice, the EU ETS is mainly a financial market used for hedging and speculation. This financial feature is regarded as a solution (hedging and liquidity) to a problem (the price risk and volatility imposed on installations) which the market has actually created itself. This paper provides an estimation of the real underpinning of the scheme, i.e. the needs of installations for allowances transfers to achieve compliance in the two first exchange periods. This estimation, which was singularly lacking in the literature, shows that compliance transactions become more and more marginal as market activity grows and that they are drowned in a whirlpool of speculation. This challenges the role of the carbon price whose financial and self-referential evaluation can obviously not reveal installations' marginal abatement costs, the condition of cost-effectiveness expected from carbon trading.
\end{abstract}

Keywords: European Union Emissions Trading Scheme, carbon market, CO2 allowance, carbon finance.

\section{Introduction}

The European Union Emissions Trading Scheme (EU ETS) was created in 2005 to reduce carbon emissions and to help the European Union reach its Kyoto commitments. Today, it controls the $\mathrm{CO}_{2}$ emissions of more than 12,000 regulated installations (mainly from industrial and power sectors, and from aviation since 2012).

Since its creation, the EU ETS has produced very mixed results and is the subject of an intense debate (see Ellerman et al., 2010; Goulder, 2014; World Bank, 2012 for a positive survey, and Lawson, 2014; Lohmann, 2006; Lohmann, 2010; Spash, 2010; Vlachou, 2014 for a critical analysis). There is a general consensus that the EU ETS encounters a major problem, namely that prices have always been excessively low and volatile. During Phase I (20052007), the pilot period, the Emission Union Allowance (EUA) price fell because of a strong over-allocation of permits. As a consequence, the European Union was in long position, i.e., owning more EUAs than its emissions level. During Phase II (2008-2012), the cap was tightened, in order to reach Kyoto commitments and improve EUA scarcity. But a new

\footnotetext{
'REGARDS (Université de Reims) et CES (Université de Paris 1)

ii LS-CREST (Genes) et REGARDS (Université de Reims)

iii REGARDS (Université de Reims)
} 
dramatic price drop occurred because of the economic crisis that impacted Europe's industrial production, and so mechanically, the level of emissions. Again, the European Union was in long position, with a growing accumulated surplus of EUA (see European Commission 2012). At the beginning of Phase III, in 2013, the EUA price fell below $€ 5$ and remains today too low to produce any incentive to switch to low-carbon technologies.

Despite these low prices and this constant over-supply of EUAs, the total volume of transactions in the EU ETS has experienced strong and solid growth. Transactions have grown by $4,790 \%$, or equivalent to nearly a 50 -fold increase, from the creation of the scheme to the end of Phase II. ${ }^{1}$ This constant growth raises the question of the nature and of the use of these transactions since, with regard to the growing accumulated surplus of EUAs, it does not seem to be driven by the installations' real needs of EUA transfers.

From a theoretical point of view, the EU ETS is a compliance market devoted to EUA trading among regulated installations seeking to cover their emissions with an equivalent number of EUAs. This is the main justification of the EU ETS: EUA trading is supposed to achieve cost-effectiveness, by equalizing installations' marginal costs. But, in practice, it is also a financial market devoted to derivatives trading among actors - regulated or not regulated - seeking hedging or speculative gains. So, the EU ETS actually fulfils two different kinds of function: it is a compliance market - the EUA market per se, the physical transfers of allowances for compliance purposes, involving at least one regulated installation and it is a financial market, i.e., a market of derivatives (mainly futures on EUAs) used for hedging or speculation.

This financial feature of the EU ETS is well known and its rising importance is often acknowledged in the literature (Ellerman et al., 2010; Daskalakis et al., 2011; World Bank, 2012; World Bank, 2013), and criticized (Lohmann, 2010; Spash, 2010). Nevertheless, the question of the actual use of these growing transactions on the EU ETS is never raised straightforwardly: no empirical study is available concerning the parts of compliance transactions or financial ones in what is allusively called carbon trading, without distinction. Our paper focuses on this issue. ${ }^{2}$ However, estimating to what extent carbon trading serves compliance purposes is not easy since the motive behind a transaction is of course impossible to ascertain. Yet, compliance transactions can be estimated through a quantification of the compliance needs of regulated installations. The EU ETS has this special characteristic compared to other commodities markets - that the physical transfers of EUAs actually 
required for compliance can be rigorously quantified since they stem from a public regulatory requirement (i.e., the cap). Such an estimation is singularly lacking in the literature. So, here, we calculate the aggregated compliance needs of all installations during Phase I and Phase II, using the data of the European Union Transaction Log (EUTL), which is the European register of the accounts of EUA owned by all installations. This estimation of the actual compliance needs describes the potential compliance market, which is the real underpinning of the scheme. Our conclusion is that the latter remains constant and has therefore become more and more marginal as carbon market activity is growing, due entirely to the derivatives market. Paraphrasing Keynes's (1936) famous analogy, ${ }^{3}$ it could be asserted that speculators are not bubbles on a steady stream of compliance, but rather that compliance trading has become a bubble in a whirlpool of speculation. Although the importance of derivatives is well-known, the small role of the compliance market has never been empirically estimated before.

This article begins by providing a critical survey of the justifications of the EU ETS as the compliance market it should be but also as the financial market it actually is and the distinction between compliance and financial transactions is clarified. We stress the fact that, besides the political reasons for creating such a financial market and developing carbon finance, ${ }^{4}$ the financial nature of the EU ETS follows from its very organization: as each installation receives its allowances one year before it has to cover its emissions, it necessarily faces uncertainty in EUA price variations and has to manage this price risk. The financial feature of the scheme is presented as the solution - helping installations hedge - to a problem - price risk - which the market entirely creates itself (Section 2). Next the article draws a picture of the EU ETS, using some scattered data on the nature of the participants (regulated or non-regulated actors) and on the kind of assets exchanged (spot or derivatives). This makes it possible to stress the dominant role of purely financial actors and the growing share of derivatives (Section 3). If this previous picture of the use of the EU ETS strongly suggests that compliance transactions represent a very limited part of overall activity, then the only way to estimate rigorously their role is to calculate the actual compliance needs of all the installations, defined as the difference between allocation and verified emissions at installation level. We then show then that compliance transactions become more and more marginal (Section 4).

Our results are important: the creation of the EU ETS is mainly justified by the theoretical cost-effectiveness of the compliance market it should be, while, in practice, it 
serves a totally different function. As a consequence, what is at stake is the fact that the carbon price cannot reflect both the average, conventional and self-referential expectations of financial actors and the marginal cost of installations. However, if we focus on this misuse of carbon trading, our purpose is not to stress that the EU ETS is not the proper kind of market it should be, i.e. that if it were the real compliance market that justified its creation, then it would be an appropriate instrument. Emissions trading only provides, at best, short term incentives to use existent and cheap modifications; it allows the bigger emitters to avoid radical innovations and finally impedes the structural changes required to switch to a lowcarbon economy (see e.g., Lohmann, 2010; Lawson, 2014). Furthermore, it produces important windfall profits and distributional injustice (Vlachou, 2014).

\section{The EU ETS: compliance versus hedging}

The EU ETS is both a market for compliance transactions, which theoretically justifies its creation. But it is also a financial market. This section provides a critical study of the justifications of these two functions - cost-effectiveness for the former and hedging and liquidity for the latter.

\subsection{The justification of the EU ETS as a compliance market: the least cost allocation}

The principle of the carbon market as a cap-and-trade instrument is quite simple. First, a global cap of emissions is set; an equivalent number of EUAs - in $\mathrm{tCO}_{2}$ equivalent ${ }^{5}$ - is issued and allocated to the regulated installations. An installation must reach compliance by surrendering the number of EUA equal to its verified emissions. This is the cap. The level of emissions reductions essentially depends on the cap and not on the trade: the incentives to reduce emissions depend on the more or less restricted allocation, since emissions cannot exceed the number of allowances issued. In other words, the same emissions reductions could be achieved with a cap without trade; e.g., with a system of non-tradable permits.

Second, since EUAs are tradable, an installation can choose between purchasing EUAs or reducing its emissions and this choice is supposed to rest on a comparison between the given allowance price and the marginal abatement cost. This is the trade. The most important justification of the EU ETS rests on the excepted efficiency of the trade, more precisely on the minimization of the social abatement cost that competitive trading in EUAs is supposed to ensure. Trading for compliance means that "long" installations (with allowance excesses, i.e. with less emissions than EUAs) trade with "short" installations (with allowance deficits) in 
order to reach compliance. Assuming that each installation faces a decreasing marginal abatement cost, it is supposed to trade until the equalization of its marginal cost to the allowance price. So carbon trading is supposed to bring all marginal costs towards equality the condition for social cost minimization. This cost-effectiveness - which is only a second best $^{6}$ - is mainly supported by the 'least cost theorem' (Montgomery, 1972).

All the theoretical justifications of carbon trading ultimately rest on this argument of cost-effectiveness. However, cost-effectiveness encounters a problem of theoretical consistency. This follows from the well-known flaw in the neoclassical theory of competitive markets: namely the lack of explanation of price formation or adjustments in a perfect competition framework with parametric prices and price taker agents. ${ }^{7}$ In the literature, this issue of the stability or convergence towards the 'least cost allocation' is generally avoided or only postulated implicitly. ${ }^{8}$ The efficiency of competitive markets requires the assumption of efficient price setting and trading.

The cost minimization expected from trading does not have theoretical foundations, and it also lacks empirical evidence. Indeed, the assumption of market adjustment efficiency is not only implicit in the theoretical justifications of competitive trading but also in empirical studies. Not surprisingly, such an implicit assumption is used when cost savings attributed to the EU ETS are estimated. Few studies are devoted to ex ante or ex post evaluations of cost savings. And these studies usually identify the outcome of the EU ETS with the least cost allocation, in order to evaluate the cost savings attributed to the scheme (Ellerman, 2010, p. 240). "Economists have managed to arrive at plausible estimates of cost savings by estimating the marginal abatement cost curves of the covered facilities, assessing the extent to which marginal abatement costs would differ across facilities under conventional regulation (...) and then calculating the extent to which these differences are eliminated" (Goulder, 2013, p. 91). In other words, cost savings are estimated under the implicit assumption that they are actually achieved. Besides, the important issue of the transaction costs involved by the creation of the EU ETS is not addressed. This issue is decisive as soon as cost savings expected from trading are used as a normative argument.

\subsection{The justification of the EU ETS as a financial market: hedging and liquidity}

According to the previous theoretical justification, trading schemes are markets devoted to installations seeking compliance at least cost. Nevertheless, the EU ETS is a 
financial market which has been designed, built and used as a financial market. Furthermore, it has a fundamental financial dimension because of its intrinsic organization: for compliance trading to occur, allowances must be allocated before compliance verification. Installations receive allowances in February of each year, more than one year before they have to surrender them in order to achieve compliance in the April of the following year. Installations thus face an uncertain EUA price: during the allocation time in February and the compliance time in April the following year, they run the risk of a price variation in the EUA. ${ }^{9}$ This risk is intrinsic to every cap-and-trade instrument and occurs because of the tradability of EUAs, i.e., because trading is the way to achieve compliance. It is used as the main justification for the financial or insurance dimension of the EU ETS: futures and forward contracts on EUAs and more generally derivatives - are regarded as necessary to help installations with hedging.

Of course, the derivatives market is also a speculative one. Speculation, defined as asset purchases and sales motivated by the hope of taking advantage of future price variations, ${ }^{10}$ is considered necessary to providing insurance by risk transfer among agents. Speculators help hedgers, i.e. regulated installations that necessarily face a price risk, to manage this risk. This is why speculation - and the market participation of purely financial agents - is considered as improving market liquidity and thus insuring efficiency. This justification for speculation on the EU ETS is usual in mainstream literature: "as with every market, the ability of market stakeholders to speculate and hedge their positions in the EU ETS is of paramount importance for sustaining a healthy volume and for ensuring market efficiency" (Daskalakis et al. 2009, p. 1240; see also Cola et al., 2012; Daskalakis et al., 2011; Ellerman et al., 2010). ${ }^{11}$ However, this previous distinction between hedging and speculation is actually not relevant: every hedging position of a regulated installation requires a speculative position to bear the risk as a counterparty; so every hedging transaction is also, at the same time, a speculative one. This is why we consider here both hedging and speculation, without distinction, as financial transactions, whose aim is primarily to transfer price risk or to take advantage of price variations.

There is a specific linkage between the two previous justifications for the EU ETS, each of them calling upon the virtue of flexibility. The EU ETS as a compliance market is justified by the theory of competitive markets without uncertainty: carbon trading is supposed to reveal and equalize marginal costs among regulated installations, the condition for social cost minimization. And the unavoidable uncertainty of price variations, intrinsic to the 
scheme, is used as a justification for the financial feature of the EU ETS. This calls for two remarks.

First, the EU ETS is supposed to provide a solution (risk hedging or insurance) to a problem (the price risk imposed on the installations) that the market itself contributed to creating: the price risk follows from the tradability of allowances, i.e., from the compliance market. Furthermore, while speculation is regarded as necessary to help firms to hedge against price volatility, one can of course consider that in fact speculation creates price volatility. Then, the price risk imposed by the compliance feature of the market is exacerbated by its financial feature.

Second, and as a consequence, behind this usual justification of speculation, what is at stake is the capacity of the carbon price to reveal the marginal costs of installations, as required by the theoretical justification of cost-effectiveness. The financial evaluation of the EUA price reflects the average expectation of actors concerning EUA price variations - in other words, the psychology of the market. From a Keynesian perspective, this evaluation is conventional and highly self-referential. And this of course has no relation to the previous role of the price - revealing and equalizing the marginal costs of installations.

\section{The use of the EU ETS}

The twofold dimension of the EU ETS raises the issue of the nature of the growing number of transactions: compliance transaction involving regulated installations seeking to cover their emissions with physical transfers of EUA or financial transactions. Even if the motive behind a transaction is impossible to identify, we use some scattered information on the nature of participants and of the assets exchanged, to show that what is allusively called carbon trading, without any distinction, involves mainly financial transactions.

\subsection{Who trades?}

In order to develop liquidity, carbon trading has been opened to everybody and not restricted to regulated installations. So quickly, besides the real compliance actors (the regulated installations), a large number of financial actors with no compliance obligation participate, including brokers, banks, traders and hedge funds. The typology of the members of the main exchange platforms (Bluenext, ECX and EEX) is as follows (CRE, 2013, p. 93): of the 236 active members, $94 \%$ are utilities or financial actors such as financial institutions or traders, while less than $6 \%$ are regulated industrial installations. ${ }^{12}$ Although no rigorous 
data are available, many sources converge in asserting that the weight of financial actors and utilities is very strong and that the activity of industry and more largely of regulated firms is marginal. Hedge funds seem to have been active since the beginning and while the market was initially led by banks and installations, the number of energy-trading firms and hedge funds has been growing since 2009 (World Bank, 2010).

Unfortunately, the breakdown of the platforms' members into power, industrial and financial sectors does not necessarily reflect their relative share of transactions. Since platforms on which transactions occur do not provide confidential data concerning the quantities exchanged by their members, it is quite impossible to know exactly the share of the total transactions that can be attributed to each kind of actor. Furthermore, transactions can also occur over-the-counter (OTC) and are of course very opaque. ${ }^{13}$ Besides, the information about the type of actors (regulated installations or non-regulated actors) does not give any rigorous information about the implicit motives of transactions: financial actors can participate as intermediaries in order to facilitate trading for regulated firms which are not directly active in the market. ${ }^{14}$ But they can also trade on their own account. At the same time, regulated actors as utilities can trade for compliance purposes but also speculate, especially when they have their own trading entities (EDF trading, Total trading and so on).

Only exhaustive investigations and inquiries about actors' behavior can provide information about their actual motives. Martin et al. (2011) provide such an inquiry based on interviews with around 800 carbon managers of manufacturing firms in European countries. They conclude that " $30 \%$ of firms that are part of the [EU ETS] only participate passively in the market; i.e. they do not consider carbon allowances as a financial asset providing opportunities. Rather, they see the cap implicit in their allowance allotment as something they merely need to comply with" (Martin et al., 2011, p. 3). Furthermore, most of them do not trade at all and, on average, they begin to sell their surpluses when they exceed 5,000 to 10,000 allowances. This relative indifference to trading opportunities confirms that industrial actors are responsible for a very limited share of the overall transactions.

\subsection{What is traded?}

In order to estimate the relative shares of compliance and financial transactions, it is also relevant to study what is traded, in other words the kind of assets exchanged. First, as already underlined, the total transactions expanded by a factor of nearly 50 in the two Phases ${ }^{15}$ - a spectacular and constant rise, which needs to be explained. 
Fig. 1: The Evolution of the Volume of Transactions in the EU ETS

\section{Authors' calculation ${ }^{16}$}

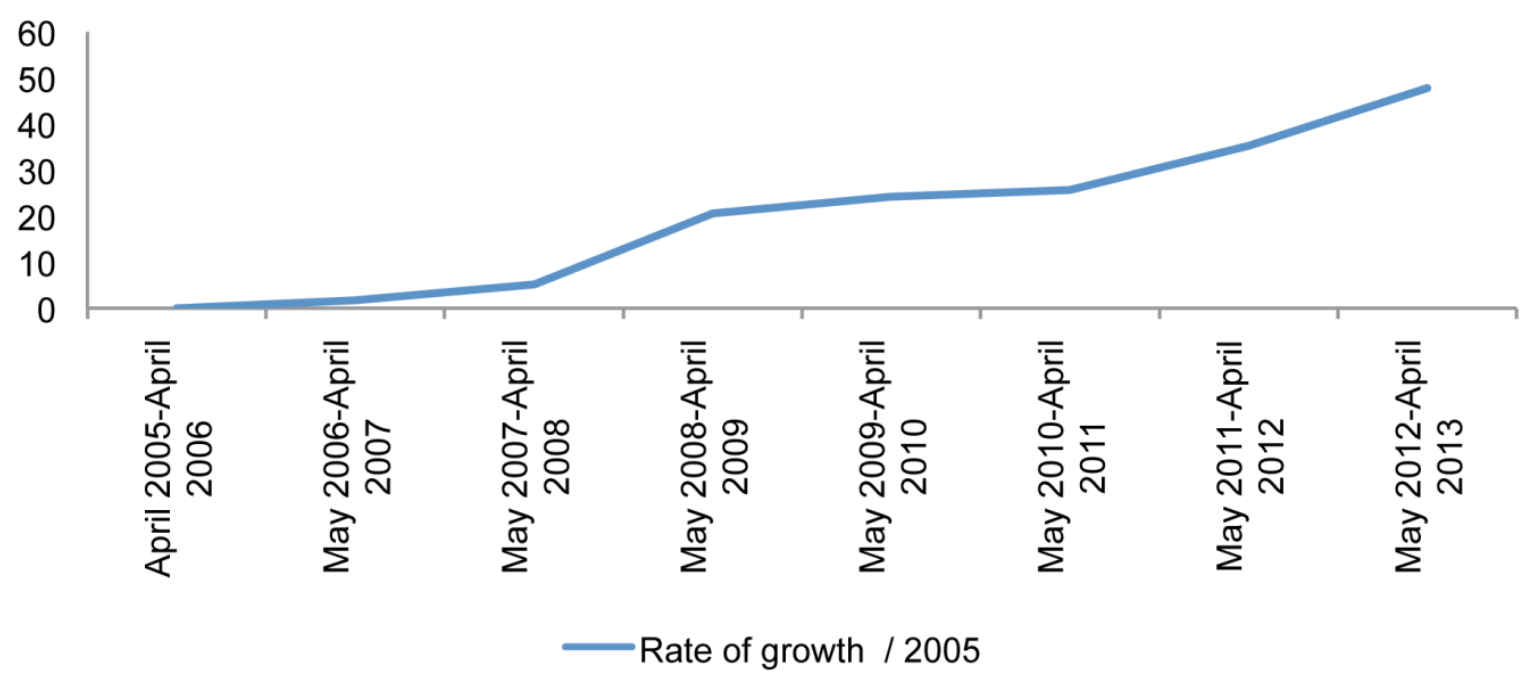

The characteristic of compliance transactions is that they necessarily involve physical transfers of EUAs. ${ }^{17}$ To estimate the relative share of compliance transactions in the growing activity, it is therefore possible to look at the relative shares of spot and derivative transactions: only spot transactions necessarily involve physical transfers of allowances while derivatives rarely do so since their use is primarily price risk hedging or speculation and not compliance. Furthermore, derivatives are largely closed before maturity. And, since its creation, the EU ETS has been led by derivatives contracts (futures, forwards but also more exotic contracts like options) that have quickly expanded to represent today nearly all the transactions in the EU ETS. Since 2010, the derivatives have accounted for $99 \%$ of the overall transactions -with spot transactions only making up the marginal, residual 1\% (see CRE, 2012; CRE, 2013, an estimation that is confirmed by Figure 4, Section 4 below). The spot transactions were exceptionally more important during 2008 and 2009 but for very special and temporary reasons: in 2008, the economic crisis was responsible for liquidity problems and the credit crunch, and a lot of regulated actors chose to monetize their allocations as soon as received them in order to have cash; besides, in 2009, the 'carousel' VAT fraud also artificially raised the number of spot trades.

Furthermore, not only are spot transactions marginal but they also become more and more marginal as financial strategies become more sophisticated. As stressed by Kossoy and 
Ambrosi (World Bank, 2010, p. 16), "as liquidity and sophistication have increased, the carbon options market has matured to the extent that it now behaves like many other options markets. The bulk of activity now comes from volatility and other relative value trades rather than asset-backed trades (i.e., financial and technical trades now account for a greater portion of market activity than do trades for compliance purposes)". The rapid rise of options is also illustrated in Figure 4 below (Section 4).

This scattered information suggests the nearly exclusive use of the market as an insurance and speculative market. But since the shares of spot and derivative trades are not the same as the shares of compliance transactions and financial ones, and since, as already stressed, the motive behind a transaction is impossible to set, the only way to rigorously estimate the share of compliance transactions in the overall activity is to look at actual compliance needs of regulated installations.

\section{The fundamental underpinning of the scheme}

The EUTL is the European register that annually records data (allocations, verified emissions and surrendered EUAs) at the installation level. We calculate the sum of the actual compliance needs of the $12,000^{18}$ installations during the two first periods (the total needs of physical EUA transfers) in order to establish the size of the potential compliance transactions. Rather surprisingly, such an estimation of these compliance needs and of its evolution since the creation of the EU ETS is lacking. The sole available study is Trotignon and Delbosc (2008), but it is limited to the first period (2005-2007) and does not take into account some missing data as is done here. ${ }^{19}$

\subsection{Evolution of the emissions and allocations}

In practice, the EUA supply is equal to the cap (i.e., the EUAs issued), while the demand for EUAs is related to emissions. In order to study what is supposed to drive EUA trading for compliance, we first look at the allocations and emissions, for each country (see Figure 2 below and the appendix for details about its construction). 


\section{Fig. 2: The Evolution of the Verified Emissions and of the EUA Allocation}

(in millions of tonnes)

\section{Authors' calculation, EUTL}

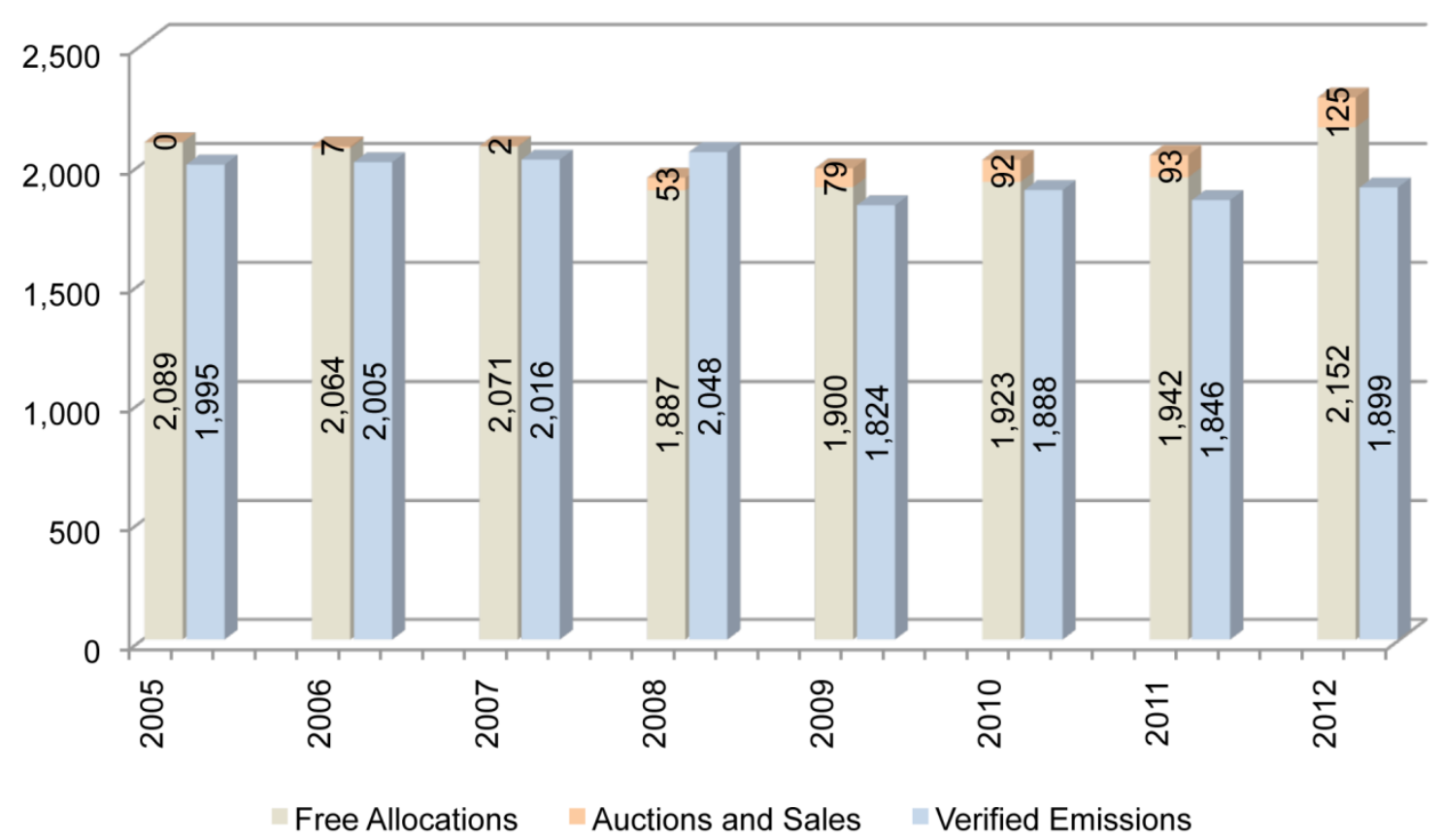

First, the growing number of transactions is not driven by the verified emissions which have been quite constant since 2005, except for the slight decrease after 2008 due to the economic crisis and to the decrease of industrial activity. Second, the transactions growth is not supported by a similar growth of the global allocation which represents the number of available EUAs or what can be called the primary market. These available EUAs have also been quite constant since the beginning of the EU ETS. Indeed, on the one hand, in 2008, the cap was restricted for the existing regulated installations in order to reach Kyoto commitments and to correct the previous over-allocation which was responsible of the sudden price drop in Phase I (for an analysis of the price volatility during Phase I, see, e.g., Ellerman and Joskow, 2008; Kruger, Oates and Pizer, 2007). But on the other hand, the available allowances have not really decreased because of the New Entrants - new Member States and newly regulated sectors, like Aircraft in 2012. Finally, Figure 2 illustrates the constant and growing oversupply of EUAs which the EU ETS has experienced since its creation, except in $2008 .{ }^{20}$ 


\subsection{The Evolution of the compliance needs}

As already stressed, supply and demand of EUAs are associated, respectively, with the levels of allocations and emissions. But the real underpinning of the scheme - which actually drives trading for compliance - is the installations' aggregate needs of EUAs for physical transfers, i.e. the sum of the discrepancies between emissions and allocations for each installation. These actual compliance needs of the 12,000 installations provide an estimation of the potential size of the compliance market. The methodology and the way the EUTL data are corrected are detailed in the appendix.

These compliance needs are obviously not given by the difference between global allocations and emissions (as illustrated in Figure 2) but are given by the aggregation of these differences at the installation level. It is the sum of all EUA deficits recorded by installations, i.e. the sum for each installation of the discrepancies between free allocation and verified emissions when this difference is negative. These aggregated short positions - the overall shortage - provide an approximation of what we call the potential compliance market. ${ }^{21}$

Fig. 3: The Evolution of Compliance Needs (in millions of tonnes)

\section{Authors' calculation, EUTL}

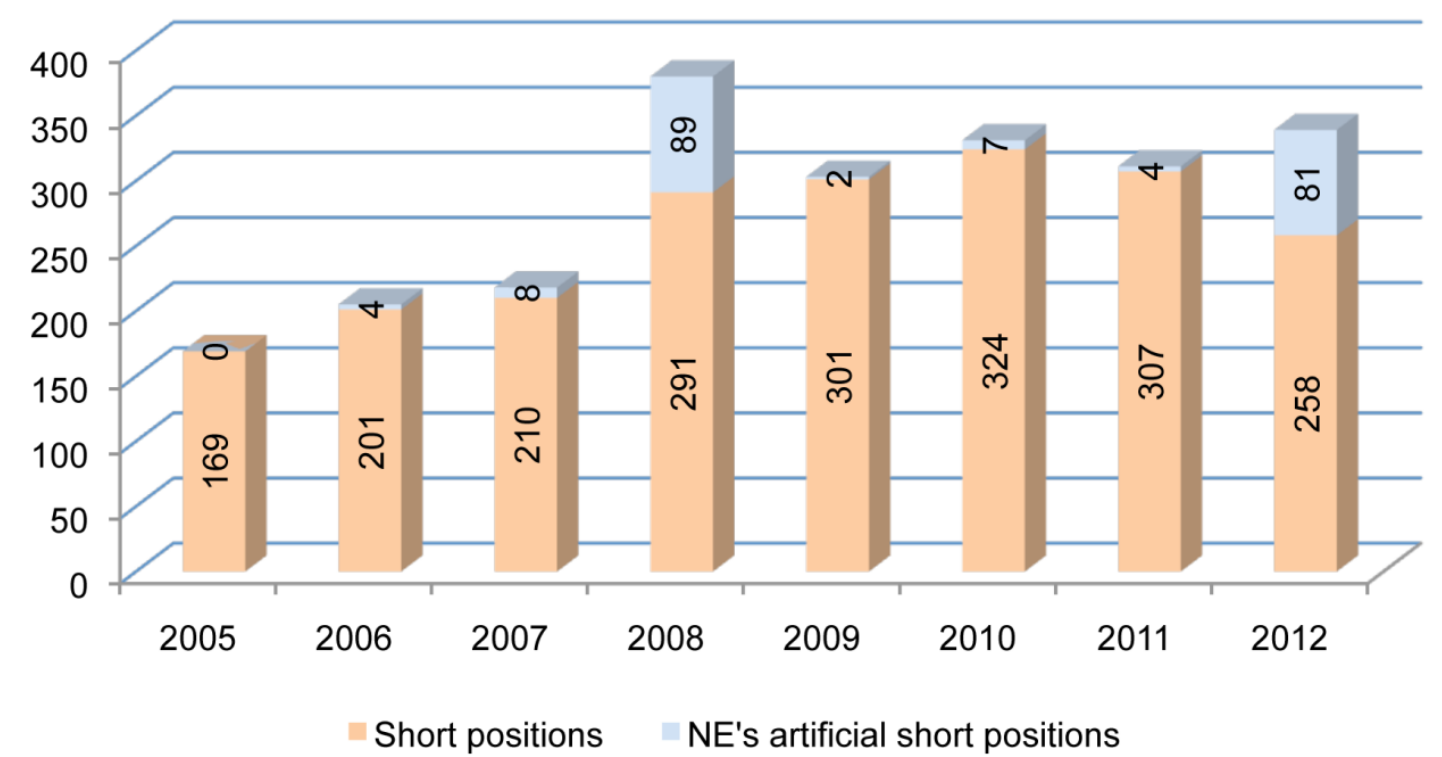

This estimation calls for two remarks. First, the relevant shortage in Figure 3 is the shortage without the New Entrants' artificial short positions. Indeed, sometimes, the EUTL 
usually records verified emissions but no allocations for new installations in the first year in which they participate. But these New Entrants actually receive EUAs from the special reserves of Member States, even if they are not recorded. These missing allocations obviously create artificial short positions. Since this phenomenon is not marginal, data are corrected to provide a better estimation, without the artificial shortage of these New Entrants (for more details, see the appendix).

Second, these compliance needs are only an approximation of the maximum size of the compliance market: actually, it is the maximum number of EUA transfers required for compliance but EUA trading is not the only way to reach compliance for short installations. Installations can use banking, borrowing and pooling to cover their emissions without purchasing EUAs. They can use EUAs banked during the previous years. They can also borrow EUAs: e.g., they can cover their emissions for one year using their allocation of the following year. Finally, a company that owns several installations can also cover its emissions by pooling: it can use the EUA excess from one installation to cover the deficit of another. In 2008, only ten companies owned a third of the EUAs and $50 \%$ of the shortage of the first period (Trotignon and Delbosc, 2008, p. 26-28). Thus, this joint management of EUAs is not a marginal way of achieving compliance. In sum, our calculation of the compliance needs is correct but it is an over-estimation of the potential compliance transactions, since a compliance need does not require necessarily a compliance transaction.

Finally, these compliance needs have not experienced the same growth as the volume exchanged. To illustrate this growing disconnection, we calculate the ratio - which we call the 'compliance transaction rate' (CTR) - between compliance needs and market activity. It states the number of transactions per compliance need (see Figure 4). It has been increasing constantly since the creation of the EU ETS and rose from 1.38 in 2005 to 19.38 in 2010 and to 33.57 in 2012, showing that the compliance market has become more and more marginal. 
Fig. 4: The Evolution of the CTR (volume of transactions /compliance needs)

\section{Authors' calculation}

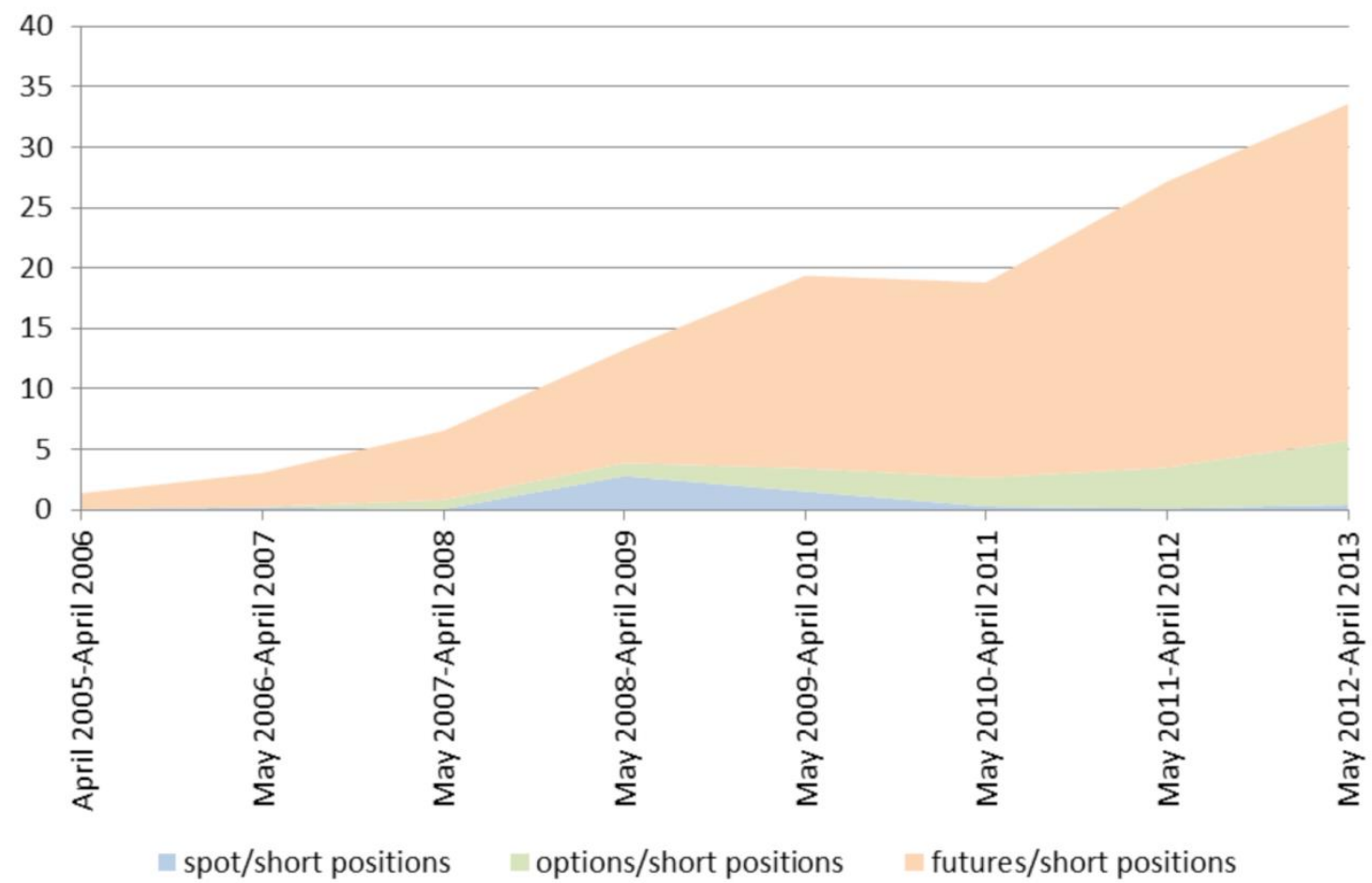

The parts of the CTR that are due to futures and more recently options transactions clearly show that carbon trading is entirely driven by the development of derivatives.

\section{Conclusion}

Compliance transactions have become a very light bubble, drowned entirely in a whirlpool of financial transactions. This conclusion is strengthened by the fact that the former is over-estimated: the compliance needs only state the maximum number of the potential transactions required for compliance as EUA trading is not the only way for short installations to cover their permits needs. According to the European Commission, "the EU ETS is widely recognized as a liquid market with a functioning infrastructure and inspires an increasing number of countries to follow the European lead and put in place domestic carbon markets" (European Commission, 2012, p. 3). Thus, since the EU ETS is today a benchmark model, it is important to provide empirical evidence of the fact that the market serves a very different function to the one that has justified its creation. 
Yet, the constant and robust growth of market activity - and mainly of derivatives trading - on the EU ETS, in a context of constant over-supply of EUAs, has been sufficient per se to suggest that carbon trading has not been driven by the underpinning of the scheme. This has sometimes been stressed in the literature. "Trading volumes soared in 2011, coinciding with the second decline in verified emissions in three years (...) These are strong indications that the collective demand for carbon permits and offsets has a limited impact in market players' trading. A considerable portion of the trades is primarily motivated by hedging, portfolio adjustments, profit taking, and arbitrage” (World Bank, 2012, p. 18).

However, no empirical estimation of these previous 'strong indications' is available and the only way to estimate the actual role of compliance transactions has been to look at actual compliance needs. Next, proponents of the scheme still consider the rise of carbon trading in general as substantial evidence of success, while it just reveals the rising disconnection with its official raison d'être.

Moreover, this financial use of carbon trading is not an unintended consequence nor is it excessive: it is intrinsic to cap-and-trade instruments. From the moment that quotas are made tradable, a price risk is imposed on the regulated actors. This is why it must be stressed that the financial feature of the scheme is presented as the solution to a problem - price risk or volatility - that the EU ETS has itself created. Given this, the recent discussion on the necessity to backload EUAs (see European Commission, 2012) - and which the European Parliament has finally approved in order to bolster dramatically low prices - seems rather derisory: price volatility will persist. The scheme is by construction unable to set the steady and sustainable carbon price that is theoretically required to drive firms' investments in lowcarbon technologies. Furthermore, the carbon price that results from the financial evaluation of the participants reflects the average expectation of price variations, i.e. the market psychology, and has obviously nothing in common with the marginal costs of installations that it is supposed to reveal and equalize. By construction, the EU ETS cannot meet the costeffectiveness that, according to its proponents, has justified its creation. 


\section{Footnotes}

${ }^{\mathrm{i}}$ Our calculation. See Section 3 for more details.

${ }^{2}$ With a focus on the EU ETS (EUA (and EUAAs, the allowances for aviation) and not on the other Kyoto Clean Development Mechanisms, i.e., not on international credits, for the purposes of simplification but also because it refers to a different kind of trade.

3 "Speculators may do not harm as bubbles on a steady stream of enterprise. But the situation is serious when enterprise becomes the bubble in a whirlpool of speculation" (Keynes, 1936, p. 159).

${ }^{4}$ Creating a financial carbon market was presented from the beginning as a great opportunity in the Stern review for example: "The transition to a low carbon economy offers growing opportunities for trading activities of all kinds, including futures trading and the development of new derivatives markets" (Stern, 2006, pp. 270-271). But our purpose is not to analyze the political economy of the EU ETS (see Spash, 2010, Paterson, 2012 and, for a study of the industry lobbying, Markussen and Svendsen, 2005).

${ }^{5}$ The creation of EUAs assumes an abstract and artificial equivalence of all emissions, independently of their geographical and technological origin, a highly questionable assumption (see, e.g., Lohmann, 2010 and Lawson, 2014).

${ }^{6}$ Pareto optimality would require exchanges between polluters and agents affected, i.e., the internalization by Arrovian market or Coasean bargaining. For a discussion and typology of 'market' internalization of externalities in a historical perspective, see (Berta and Bertrand, 2014).

${ }^{7}$ The absence of stability of Walrasian markets, as set out in the Sonnenschein-Mantel-Debreu theorem (1974) seems to be completely ignored in the literature on trading schemes, which always assumes that competitive equilibrium is reached (see Baumol and Oates, 1988, for a general equilibrium approach). The problem obviously remains in partial equilibrium, since the presence of an auctioneer to set price adjustments is always required.

${ }^{8}$ Montgomery's theorem is just a kind of existence proof of a competitive cost-efficient equilibrium and never questions its stability. For a detailed analysis of Montgomery (1972), see (Berta, 2006).

${ }^{9}$ They also encounter a compliance risk since they do not know exactly what their emissions level will be at the end of the compliance year. But this risk could be managed with banking, borrowing or purchasing EUAs just before April.

${ }^{10}$ This is the usual meaning given by Kaldor (1939), and also adopted by Keynes: speculation " $[\ldots]$ may be defined as the purchase (or sale) of goods with a view to resale (repurchase) at a later date, where the motive behind such action is the expectation of a change in the relevant prices relatively to the ruling price and not a gain through their use, or any kind of transformation effected in them, or their transfer between markets".

${ }^{11}$ Of course, if the derivatives market is usually justified by this necessity of risk transfers between hedging installations and speculators, derivatives can also involve two speculators that, by definition, do not face any price risk.

${ }^{12}$ This breakdown is quite constant (CRE, 2012, p. 83).

${ }^{13}$ See (CRE, 2012, p. 80; CRE, 2013, p. 99) for an estimation of OTC transactions accounting for around 20$25 \%$ of all the assets exchanged.

${ }^{14}$ Small regulated firms seem to use such intermediaries, since being active on platforms is not costless (Prada, 2010). 
${ }^{15}$ The volume is the sum of spot, futures and options trades. It is set per compliance year (i.e. from May to April the following year, April being the time installations have to cover their emissions and to surrender EUAs) and not per calendar year. This choice is relevant since transactions are to be compared, in the next section, to compliance needs. Besides, transactions on ICE are aggregated, as this is the main platform that records $96 \%$ of the transactions (ICE, 2013, p. 12). But we do not take into account OTC. As a result, the exchanged volume is slightly under-estimated.

${ }^{16}$ Spot prices are taken from Tendance carbone monthly letter, futures from ICE monthly data, options from ICE monthly data (except options for 2012 and 2013: these volumes are our estimates as ICE options on EUAs are no longer registered separately).

${ }^{17}$ The EUTL could give information about physical transfers of EUAs since this register records all the physical accounts of EUAs, from regulated installations or non-regulated actors. It is "the backbone of the spot market" (De Perthuis, 2011, p. 8) and could give information on all the physical transfers, and especially on the transfers from regulated installations between the time they receive allowances and the time they surrender part of them to achieve compliance the following year. But this information is not available for 5 years.

${ }^{18}$ They were 12,000 , in 2013, but we calculated that 15,052 installations were regulated in 2005-2012, if all the closed ones are included.

${ }^{19}$ This involves especially the artificial compliance needs that some New Entrants can create, as we will see below. Their study is also used in Ellerman et al. (2010).

${ }^{20}$ As already stressed, the paper focuses on the EU ETS. But the EUA surplus is actually larger if we take into account the international Kyoto credits that installations can also use to cover their emissions: using these credits frees up EUAs that do not have to be surrendered for compliance. For example, during 2008-2011, 549 million units of credits have been used for compliance (see European Commission, 2012).

${ }^{21}$ Except in 2008, the short positions are always below the long positions, reflecting the constant over-supply encountered by the EU ETS, the growing surplus of EUA (an accumulated surplus of 955 million units by early 2012 according to the European Commission, 2012). Since transactions in disequilibrium are always limited by the 'short side' - i.e., the constrained side - of the market, it is the short and not the long positions that give an estimation of the potential transactions for compliance.

\section{Appendix: Methodology on the EUTL}

As the EUTL is not user-friendly, the European Environmental Agency (EEA) has developed a tool, the EU ETS data viewer, which gives data at the aggregated level. However, it does not provide data at the installation level and it uses calendar years rather than compliance years. This is why we use EUTL data directly here. For each installation, the difference between allocation in February and verified emissions recorded in April the following year (allocation of year $n$ - verified emissions of $n+1$ ) is calculated. These positions, when installations are in 'short positions', are aggregated in order to calculate the overall shortage. 
This calls for two remarks. First, the EUTL records the level of the verified emissions of each installation as well as the number of surrendered allowances. Unfortunately, verified emissions and surrendered allowances, even if they are very close, are not always exactly equal, i.e., installations do not always reach compliance. There is no available information about the reasons that eventually lead firms not to reach compliance (for example, if it is just a problem of missing data in the EUTL). Since the actual compliance needs are of interest here, we have chosen to use the level of verified emissions.

Second, the EUTL does not always give a true and fair picture of reality. As stressed by the European Environmental Agency (EEA), "the data contained in the EUTL is undergoing constant changes, for example due to: installations entering or leaving the EU ETS; addition of missing information, e.g., late verified emission reports; correction of emission reports or inaccurate data in national registries; court decisions on the allocation decisions. In most cases these changes are small and have no significant effect on the overall analysis" (EEA, 2013, p. 7). These constant changes explain the scattered missing or inaccurate data. Although these changes remain marginal, we choose to correct some of the missing or inaccurate data when it impacts the short positions and when consistent corrections are possible. These corrections are detailed below.

\section{Installations with missing verified emissions}

Several installations, in every country, record allocations each year but have missing verified emissions (i.e., emissions equal to zero) for one year (or several years), but not for the following years. In other words, emissions disappear just for one or few years. Since such installations are not installations leaving the scheme (with zero emissions in the year they leave), we chose to correct the missing data: Emissions, when lacking, are considered to be equal to the emission levels of the year recorded emissions reappear. As recorded emissions are cumulated in the EUTL, we use the following rule: when for example, an installation records allocations and cumulated emissions respectively equal to $(a, x)$ for year $n,(a, 0)$ year $n+1$ and $(a, y)$ year $n+2$, we assume $(a, x+(y-x) / 2)$ for year $n+1$. In sum, we avoid creating artificial shorts in the year the verified emissions 'reappear'.

\section{New Entrants}

Another problem to manage was the missing data for New Entrants. New Entrants receive allocations as soon as they participate in the EU ETS, since Member States keep 'New 
Entrants Reserves NER' (NER) in order to deal with such situations. Nevertheless, many of these new installations have no EUA allocation recorded in the EUTL the year they enter (and usually only for this first year because of a delay in the recording), while they record surrendered EUAs and verified emissions. According to the EUTL data, they are in short positions the year they enter while, actually, this may not necessarily be so. Working with the data as it stands artificially creates strong short positions for these New Entrants. As each national registry seems to deal individually with these missing allocations for New Entrants (sometimes recorded the next year, sometimes not), no consistent corrections can be brought. But since New Entrants are not marginal for the overall analysis, and especially for the calculation of the short positions, two calculations are provided: one of the total short positions, using new entrant data as it is, and another one without the New Entrants positions just for the year they enter. This makes possible to give an estimation of the artificial shortage created by the missing allocations. We consider here that New Entrants are all installations that are recorded for EUA allocation and verified emissions respectively: $(0,0)$ or (nothing, nothing) before year $n ;(0, x)$ for year $n$, and $(y, y)$ for year $n+1$.

\section{Bibliography}

Berta, N. 2006. Fondements théoriques des marchés de permis négociables : le théorème de Montgomery, Economie Appliquée, vol. LIX, no. 4, 59-75

Berta, N., Bertrand, E. 2014. Market internalization of externalities: what is failing?, Journal of History of Economic Thought, vol. 36, no. 3, 331-357

Cola, P., Germain, M. and Van Steenberghe, V. 2012. Environmental Policy and Speculation on Markets for Emission Permits, Economica, vol. 79, 152-182

Convery, F. J. 2009. Origins and Development of the EU ETS, Environmental Resource Economics, vol. 43, 391-412

Commission de régulation de l'énergie (CRE). 2012. Le fonctionnement des marchés de gros de l'électricité, du CO2 et du gaz naturel, rapport 2011-2012

Commission de régulation de l'énergie (CRE) 2013. Le fonctionnement des marchés de gros de l'électricité, du CO2 et du gaz naturel, rapport 2012-2013

Daskalakis, G., Markellos, R.N. and Psychoyios, D. 2009. Modeling $\mathrm{CO}_{2}$ emission allowance prices and derivatives : Evidence from the European trading scheme, Journal of Banking \& Finance, vol. 33, 1230-1241 
Daskalakis G., Ibikunle, G. and Diaz-Rainey, I. 2011. The $\mathrm{CO}_{2}$ Trading Market in Europe: A Financial Perspective, pp. 51-67 in Dorsman, A., Westerman, W., Karan, M., Arslan, O. (eds), Financial Aspects in Energy : A European Perspective, Springer, Berlin / Heidelberg

De Perthuis, C. 2011. Carbon markets regulation: The case for CO2 Central Bank, Les cahiers de la Chaire Economie du Climat, no.10, Paris-Dauphine University, CDC Climat

Ellerman, A. D., Convery, F. J. and de Perthuis, C. 2010. Pricing Carbon: The European Union Emissions Trading Scheme, Pearson, Paris

Ellerman, A.D. and Joskow, P.L. 2008. The European Union's Emissions Trading System in Perspective, Pew Center on Global Climate Change, MIT, Arlington

European Commission. 2012. The State of the European Carbon Market in 2012, Report from the Commission to the European Parliament and the Council

European Environment Agency. 2013. EU ETS Data Viewer, User Manual and Background Note version 4.1, june

Goulder, L. H. 2014. Markets for pollution allowances: What ere the (new) lessons?, Journal of Economic Perspectives, vol. 27, no. 1, 87-102

ICE. 2013. The Emissions Market. ICE Futures Europe, November

Kaldor, N. 1939. Speculation and economic activity, Review of Economic Studies, vol. 7, no. $1,1-27$

Keynes, J. M. 1936. The General Theory of Employment, Interest and Money, London: MacMillan

Kruger, J., Oates, E. and Pizer, W.A. 2007. Decentralization in the EU ETS and lessons for global policy, Review of Environmental Economics and Policy, vol. 1, no. 1, 88-111

Lohmann, L. 2005. Marketing carbon dumps: commodification, calculation and counterfactuals in climate change mitigation, Science as Culture, vol. 14, no. 3, 203-35

Lohmann, L. 2006. Carbon Trading: A Critical Conversation on Climate Change Privatisation and Power, Uppsala, Dag Hammarskjold Foundation

Lohmann, L. 2010. Uncertainty markets and carbon markets: variations on Polanyian themes, New Political Economy, vol. 15, 225-54

Martin, R., Muûls, M. and Wagner, U. 2011. Climate Change, Investment and Carbon Markets and Prices - Evidence form manager interviews, Carbon Pricing for Low Carbon Investment Project.

Markussen, P. and Svendsen, G. T. 2005. Industry lobbying and the political economy of GHG trade in the European Union, Energy Policy, vol. 33, 245-255 
Montgomery, W. D. 1972. Markets in licenses and Efficient Pollution Control Programs, Journal of Economic Theory, vol. 5, 395-418

Newell, P. 2012, The political economy of carbon markets: the CDM and other stories. Climate Policy, vol. 12, no. 1, 135-139

Paterson, M. 2012. Who and what are carbon markets for? Politics and the development of climate policy, Climate Policy, vol. 12, no. 1, 82-97

Prada, M., 2010. La Régulation des Marchés du CO2. Rapport de 1'Inspection Générale des Finances, Ministère de l'économie, de l'industrie et de l'emploi, La Documentation Française, Paris

Spash, C. L., 2010. The brave new world of carbon trading, New Political Economy, vol. 15, no. $2,169-195$

Stern, N. 2006. Economics of Global Change - The Stern Review, http:/www.hmtreasury.gov.uk/independent_reviews/stern_review_economics_climate_change/stern_review _report.cfm

Trotignon, R., Delbosc, A. 2008. Echanges de quotas en période d'essai du marché européen du CO2 : ce que révèle le CITL. Etude Climat $n^{\circ} 13$, CDC Mission Climat, Paris

Vlachou, A. 2014. The European Union's Emissions Trading System, Cambridge Journal of Economics, vol. 38, 127-15.

World Bank. 2010. State and Trends of the Carbon Market 2010, World Bank Report, Washington DC.

World Bank. 2012. State and Trends of the Carbon Market 2012, World Bank Report, Washington DC.

World Bank. 2014. State and Trends of Carbon Pricing 2014, World Bank Report, Washington DC. 